\title{
Brenda Milner: 100 Years from the Birthday
}

\author{
Eresko $\mathrm{SO}^{1 *}$, Trofimov $\mathrm{AN}^{2}$, Airapetov $\mathrm{MI}^{2,3}$ and Sevostyanova $\mathrm{NN}^{4}$ \\ ${ }^{1}$ Saint-Petersburg State University, Russia \\ ${ }^{2}$ Saint Petersburg, Akademika, Russia \\ ${ }^{3}$ Saint Petersburg State Pediatric Medical University, Russia \\ ${ }^{4}$ Yaroslav-the-Wise Novgorod State University, Russia
}

*Corresponding author: Eresko SO, Saint-Petersburg State University, 199034,

St. Petersburg, Universitetskaya Emb, 7-9, Russia.

Received Date: January 21, 2019

Published Date: May 23, 2019

\section{Short Communication}

Brenda Milner is a renowned British-Canadian neuropsychologist known as "the founder of neuropsychology". She was born about 100 years ago, and as a Cambridge graduate, she started her research career of a neurobiologist and psychologist in 1940s. Her comprehensive contribution to the development of clinical neuropsychology thereafter was marked by several awards including the Balzan Prize for Cognitive Neuroscience in 2009 and the Kavli Prize in Neuroscience in 2014 (shared with Marcus Raichle and John O'Keefe), as well as memberships in the Royal Society of London, the Royal Society of Canada and the National Academy of Sciences. She holds more than 20 honorary degrees at universities across Europe, Canada and the USA. Currently, Brenda Milner keeps working as a professor in the Department of Neurology and Neurosurgery at McGill University (Montreal, Canada) and a professor of Psychology at the Montreal Neurological Institute with her research mainly focused on the inter-hemispheric interactions [1-5] (Figure 1).

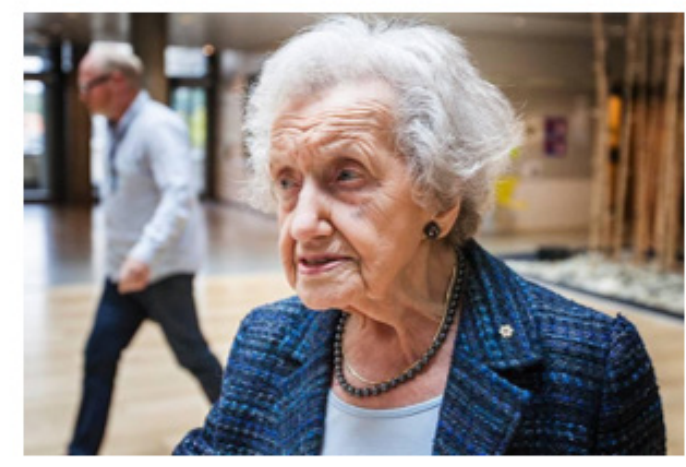

Figure 1: If you find real temptation, real excitement somewhere else, don't be afraid to change. Brenda Milner.
One of important contributions in neuropsychology by Brenda Milner was brought to the study of mechanisms of memory worsening in elderly. Due to the fact that most diseases associated with aging are characterized by memory disorders, this topic finds its high importance in the studies of gerontology. Working with patients who suffered the brain lobes removal, Brenda Milner received many new data on the complex and hierarchical organization of memory mechanisms in the brain. A unique case of an 86-year-old patient M.P. showed the brain changes due to lobectomy to remain stable for dozens of years. Neuropsychological methods have shown that in her 86 years, the patient with lobectomy was in no way inferior to her peers. Minor violations of verbal memory have been preserved throughout life without any deterioration. This long-term and rather interesting study is described in detail in the present article [5-8] (Figure 2).

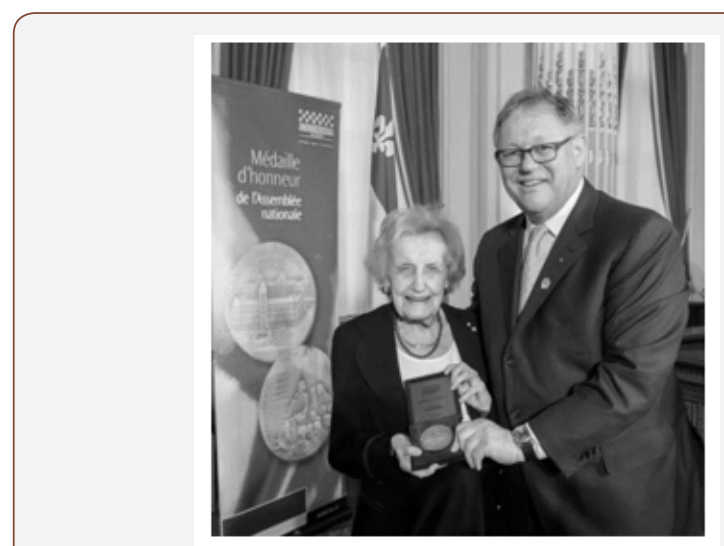

Figure 2: The ceremony of awarding medals of honor.

\section{Acknowledgment}

None. 


\section{Conflicts of Interest}

No conflicts of interest

\section{References}

1. Banks SJ, Feindel W, Milner B, Jones-Gotman M (2014) Cognitive function fifty-six years after surgical treatment of temporal lobe epilepsy: A case study. Epilepsy Behav Case Rep 2: 31-36.

2. Corkin S (1984) Lasting consequences of bilateral medial temporal lobectomy: clinical course and experimental findings in H.M. Sem inNeurol 4: 249-259.

3. Holdstock JS, Crane J, Bachorowski JA, Milner B (2010) Equivalent activation of the hippocampus by face-face and face-laugh paired associate learning and recognition. Neuropsychologia 48(13): 37573771.
4. Milner B, Branch C, Rasmussen T (1962) Study of short-term memory after intracarotid injection of sodium amytal. Trans Am Neurology Ass 87: 224-226.

5. Milner B, Klein D (2016) Loss of recent memory after bilateral hippocampal lesions: memory and memories-looking back and looking forward. J Neurol Neurosurg Psychiatry 87(3): 230.

6. Milner B, Squire LR,Kandel ER (1998)Cognitive Neuroscience and the Study of Memory. Neuron 20(3): 445-468.

7. Roth H, Sommer BW (2011) Interview with Brenda Milner. Montreal Neurological Institute and Hospital Montreal, Canada.

8. Squire LR (1998) The History of Neuroscience in Autobiography. San Diego: Academic, Oxford University Press, UK. 